\title{
Die ungarischen etymologischen Forschungen und das neue ungarische etymologische Wörterbuch
}

1. Bevor ich zum eigentlichen Thema meines Aufsatzes, zur skizzenhaften Darstellung der Arbeiten und der Problematik des in Angriff genommenen neuen ungarischen etymologischen Wörterbuches übergehe, möchte ich einen kurzen Rückblick werfen auf die Vergangenheit der ungarischen etymologischen Forschungen. Dieser Rückblick ist aus zwei miteinander eng zusammenhängenden Gründen nützlich und notwendig. Einerseits beeinflusst und bestimmt dic Vergangenheit dieser Forschungen - wie es im allgemeinen in der freschichte der Wissenszweige zu sein pflegt - die Gegenwart der ungarischen etymologischen Forschungen, bzw. auch das diese Gegenwart beherrschende und repräsentierende Wörterbuch in seinem Charakter, seiner Beschaffenheit und seiner Problematik. Andererseits erntet das Wörterbuch - als Zusammenfassung der bisherigen etymologischen Forschungen - im wesentlichen die Früchte der unermüdlichen Arbeit von früheren Iinguistengenerationen; im Veroleich zu den bisher vorhandenen bietrt es riel Neues in Inhalt und Methode, auch ist es bestrebt. dis in den bisherigen Forschungen gesimmelte umfangreiche Material auf zeitgemässem Niveau, mit der dem heutigen Stand der Wissenschaft entsprechenden Kritik vorzulegen.

2. Im allgemeinen muss bemerkt werden, dass die ungarischen wissenschaftlichen Kreise, ja auch das gebildetere ungarische Publikum ausserhalb der Sprachwissenschaft von jeher bis zum heutigen Tag den etymologischen Problemen des Gemeinwortschatzes der ungarischen Sprache sowie auch der Eigennamen ein überdurchschnittlich orosses Interesse entgegengebracht haben. Dieses Interesse wird wahrscheinlich 
mit der herkunftsmässig ansserordentlich gegliederten, vielfarbigen Beschaffenheit, mit der an Besonderheiten reichen Problematik des ungarischen Wortschatzes zusammenhängen, deren Aufdeckung in allen Einzelheiton die Linguistenkreise zu immer neuer Arbeit anspornte und ausserdem auch dio Aufmerksamkeit der für sprachliche Dinge empfänglichen, sprachwissenschaftlich jedoch nicht ausgrebildeten Menschen weckte. Worin auch immer dieses ausserordentliche Interesse wurzeln mag, Tatsache ist, dass die etymologischen Untersuchungen einen der ältesten und in allen Zeiten quantitativ wie qualitativ am meisten gepflegten Zweig der ungarischen Sprachwissenschaft bildeten; von allen Ergebnissen der Sprachwissenschaft ist die Etymologie jener Bereich, der sowohl in der Vergangenheit als auch in der Gegenwart das gebildetere breite Publikum am stärksten anzieht.

Nach alledem nimmt es uns vielleicht nicht wunder, dass der Chronist P. dictus Magister, oder wie er im allgemeinen genannt wird, Anonymus, der erste ungarische Geschichtsschreiber aus dem 12. Jahrhundert, in seinem umfangreichen Werk, (iesta Ihungarorum, eine ganze Reihe von ungarischen Orts- und Personennamen zu deuten versucht, indem er sie mit ungarischen Gemeinwörtern vergleicht, ja manchmal auch ausführlich erklärt. Man kann wohl ohne viel zu übertreiben sagen, dass Anonymus der erste ungarische Etymologe war. Dies ist freilich nur eine wissenschaftsgeschichtliche Kuriosität, doch werden dadurch die auch zeitlich tiefen Wurzeln des etymologischen Interesses in Ungarn gut gekennzeichnet.

Ich möchte mich keineswegs in die reichlich wuchernden wissenschaftsgeschichtlichen Einzelheiten der frühen Zeit versenken, denn dann hätte ich ja für den hinsichtlich unseres Themas wichtigeren Zeitabschnitt, insbesondere für die Gegenwart, bzw. für unser neues Wörterbuch keine Zeit mehr. So will ich nur flüchtig einige charakteristische Momente andeuten.

In seinem vielsprachigen Wörterbuch führt Verantius Faustus am Ende des 16. Jahrhunderts eine ganze Liste von slawischen Lehnwörtern der ungarischen Sprache auf. Im 17. und noch mehr im 18. Jahrhundert habon wir Büchor sprachlichen, 
geschichtlichen und literarischen Inhalts zu Dutzenden; in diesen werden etymologische Fragen, meistens die Problematik der verschiedenen Lehnwörterschichten oft auffallend eingehend besprochen. Die am Ende des 18. Jahrhunderts erschienene Debrecener "Magyar Grammatika" (Ungarische (irammatik) gibt zum Beispiel bereits einen ganzen Querschnitt von der Herkunft unseres Wortbestandes; neben der Erörterung der verschiedenen Lehnwörtergruppen (griechisch, lateinisch, türkisch, slawisch, deutsch, franzïsisch usw.) werden hier auch die ursprünglichen sowie innersprachlich entstandenen Wörter besprochen. Wie bekannt, fällt anch der Anfang der finnischngrischen Sprachvergleichung in diese Zeit, mit der die Namen eines János Sajnovics und eines Sámuel (ryarmathi untrennbar verbunden sind.

Diese Vorereignisse der ungarischen etymologischen Forschungen spiegeln natürlich das Niveau der damaligen Gelehrsamkeit wider und sind auch danach zu bewerten. Die Vergleiche beruhen vorwiegend auf formalen und bedentungsmässigen Ähnlichkeiten, allgemeinere sprachliche Gesetzmässigkeiten werden nur höchst selten erkannt und angewendet. Es versteht sich ron selbst, dass sich dabei Ungenauigkeiten, übereilt naive Feststellungen, ja grobe Irrtümer finden. Zugleich aber enthalten diese Erklärungen reichlich Lösungen, die auch dem heutigen Forscher richtig erscheinen, die zwar nicht als Ergebnis methodischer Verfahrensweisen und überzeugender Erörterungen entstanden, doch letzten Endes auch heute noch wahr sind. Mit dem ungarischen etymologischen Material aus dem 17. und 18. Jahrhundert, das in erster Linie von wissenschiaftsgeschichtlichem Interesse und Wert ist, könnten Bände gefüllt werden.

In der ersten Hälfte des 19. Jahrhunderts nimmt die etymologische Literatur in Ungarn, wie auch im allgemeinen anderswo, eher an Umfang zu, ohne ihre Qualität und ihre Methoden wesentlich zu verbessern. Es ist bezeichnend, dass die meisten der vielen ein- und mehrsprachigen Wörterbücher im Ungarn dieser Zeit auch etymologische Ausführungen enthalten und als Vorarbeiten der späteren etymologischen Wörterbücher betrachtet werden können. Unter diesen verdient, eher vom 
thematischen als vom methodischen Gesichtspunkt aus, das vierbändige Wörterbuch von József Kassai aus den dreissiger Jahren des vorigen Jahrhunderts besondere Beachtung; darin wird der Herleitung von innersprachlich entstandenen ungarischen Wörtern ein bedeutender Platz eingeräumt, mit vie] Naivität und mit Irrtümern, aber zugleich mit Erkenntnissen, die sich später als richtig erwiesen haben.

Zeitlich gehört das erste, wirklich grossangelegte einsprachige ungarische Wörterbuch von Czuczor und Fogarasi in die zweite Hälfte des Jahrhunderts, doch zeigt es in seinem ganzen Gepräge und in seinen etymologischen Stellungnahmen mehr die Eigenheiten der früheren Epoche. Dieses Werk spielt in der Geschichte der ungarischen etymologischen Forschungen eine überaus interessante Rolle. Es fährt in den Spuren Kassais fort und legt ausserordentliches Gewicht auf die etymologische Erörterung der innersprachlich entstandenen Elemente, innerhalb dieser auf die Gl ederung nach Wortfamilien, auf die Onomatopoetik usw. Obwohl es dies mit seltener Erfindungsgabe, mit vielen guten Einfällen tat und die neuesten Forschungen eine ganze Reihe seiner bercits vergessenen Erkenntnisse methodisch bestätigten, sind seine etymologischen Verdienste durch die vielen, hier nicht anzuführenden Fehler, durch seine Naivität, die der Kassais ähnelt, bereits bei den Zeitgenossen und hauptsächlich bei den folgenden Linguistengenerationen vollends in Abrede gestellt worden; was noch schlimmer war: die etymologische Beschäftigung mit den innersprachlich entstandenen Elementen der ungarischen Sprache wurde für lange Zeit diskreditiert.

Die allgemeine Entwicklung der geschichtlich-vergleichenden Sprachwissenschaft, danach der Einfluss der jungerammatischen Schule haben in der zweiten Hälfte des vorigen Jahrhunderts auch in Ungarn die höher entwickelten Formen der etymologischen Forschung herausgebildet, die in erster Linie durch die strenge Registrierung der Lautgesetze charakterisiert sind und von der Lautgeschichte beherrscht werden. In diese Zeit fällt der Aufschwung der finnisch-ugrischen vergleichenden Sprachwissenschaft durch József Budenz in Ungarn und parallel damit die erste methodischere Bestandaufnahme des 
urtümlichen finnisch-ugrischen Wortschatzes des Ungarischen. Auf dem Gebiet der Lehnwortforschung wurde zunächst die Turkologie stärker belebt, aber auch die Untersuchung der slawischen Lehnwörter des Ungarischen nahm einen nicht geringen Aufschwung. Besonders die auf diesen beiden Forschungsgebieten erreichten Kenntnisse haben unser heutiges Wissen um viel wertvolle, dauerhafte Ergebnisse bereichert. Jit diesem qualitativen Sprung hängt es zusammen, dass auch das neue ungarische etymologische Wörterbuch die etymologische Literatur rom Anfang dieser Epoche, dem Jahre 1862, nämlich vom Beginn der Zeitschrift "Xyelvtudományi Közlemények" (Sprachwissenschaftliche Mitteilungen) sachlich und bibliographisch berücksichtigt, während es die früheren trotz der wertvollen Teilergebnisse - nur als wissenschaftsgeschichtliche Vorereignisse betrachtet.

Als die folgende Epoche der ungarischen etymologischen Forschung können die ersten vier Jahrzehnte dieses Jahrhunderts angesprochen werden. Auf thematischem Gebiet beginnt die Erforschung der Lehnwörter im Ungarischen vorzuherrschen; ausser den vorwiegend in den Zeitschriften angesammelten überaus reichlichen Forschungsmaterialien werden grössere und kleinere Monographien über sozusagen alle Schichten der vielartigen Lehnwörter im Ungarischen geschrieben. Die führende Gestalt dieses neben der Lautgeschichte auch jetzt noch stärksten Zweiges der ungarischen Sprachwissenschaft, des Etymologisierens, ist János Yelich, der in vielen hundert Artikeln und manchen Monographien die Problematik des I ehnwörter verschiedenster Herkunft mit ausserordentlichem Scharfsinn und erfolgreich aufgedeckt hat. Auch Zoltán Gombocz hat bedeutende Verdienste, ror allem bei der Untersuchung der türkischen Lehnwörter. Auch die Erforschung der Wörter finnisch-ugrischer Herkunft wurde nicht unterbrochen, und in gewisser Hinsicht wandte sich die Aufmerksamkeit auch der Etymologie der Wörter innersprachlicher Entstehung zu. Auf dem ersteren Gebiet ist die Synthese durch Júzsef Szinnyeis "Magyar nyelvhasonlítás" (Ungarische Sprachvergleichung) gekennzeichnet, auf dem letzteren ist die Tätigkeit von Dezső Pais und Gedeon Mószöly ron Bedeutung. Obwohl die kom- 
plexere Methode des Etymologisierens in dieser Zeit bereits stark in den Vordergrund zu treten beginnt, wird die Methode grundlegend noch immer durch die Lautgeschichte gekennzeichnet. Die sprachgeschichtlichen Quellenausgaben haben zugenommen, das ungarische sprachgeschichtliche Wörterbuch und das ungarische Dialektwörterbuch sind erschienen, und dies verhilft auch in grösserem Masse als früher zur Entfaltung der Wortgeschichte in Gemeinschaft mit dem Etymologisieren.

In diese Zeit fällt ferner die Veröffentlichung der Forschungscrgebnisse in einer moderneren Form, in etymologischen Wörterbüchern. Im Jahre 1914 beginnt das Unternehmen von Gombocz und Melich, "Magyar Etymológiai Szótár" (Ungarisches Etymologisches Wörterbuch), ein Werk, das durch seinen philologischen Apparat und sein allgemeines Niveau hervorragt. Das Werk hat die damalige europäische Iinguistik mit Bewunderung erfüllt, konnte ausser von Wartburgs französischem etymologischem Wörterbuch in mancher Hinsicht bis heute nirgends erreicht werden und bedarf auch an dieser Stelle kaum einer besonderen Vorstellung. Seinen Werten und Ergebnissen tut weder das Erscheinen in Heften über drei Jahrzehnte viel Abbruch, noch die innere Disproportion, noch der Umstand, dass ein übersichtlicher Aufbau der Wortartikel nicht zu den Tugenden der Verfasser, hauptsächlich von Melich, gehörte. Bedeutend folgenschwerer war, dass das grossangelegte Unternehmen - infolge von vielerlei Gründen am Anfang des Buchstaben $g$ abgebrochen wurde, und demnach nur ungefähr ein Drittel des urigarischen Wortschatzes erfasst hat.

Das zweite, bedeutend kleiner angelegte, aber rasch vollendete und vollständige etymologische Wörterbuch ist das Werk von Géza Bárczi. Sein "Magyar Szófejtő Szútár" (Ungarisches etymologisches Wörterbuch), das in erster Linie den Ansprüchen des gebildeteren breiten Publikums gerecht werden sollte, kann auch von Fachleuten gut benutzt werden; diese Tatsache sagt über seine Verdienste mehr als alles andere aus. Dieses in seiner Bündigkeit und selbst mit seinem beschränkten Wortmaterial klassische Werk dürfte den meisten Lesern dieses Aufsatzes gut bekannt sein. 
Das im Jahre 1941 erschienene Wörterbuch Bárczis bedeutete ungefähr den Abschluss der vorhin behandelten Epoche, es ist aber Einleitung und Ansporn zu den Forschungen der vergangenen zwei Jahrzehnte geworden. Es schöpfte seine Triebkraft daraus, dass es als Synthese darauf hinwies, dass sehr viele Einzelwörter und Wortgruppen in früheren Forschungen mehr oder weniger vernachlässigt worden waren, zum Teil aber auch daraus, dass es noch klarer als das Wörterbuch von Gombocz und Melich herausstellte, dass die Herkunft eines bedeutenden Teils der ungarischen Sprache in ihr selbst zu suchen ist, oder zumindest nur mit der Kenntnis der Problematik der ungarischen Sprachforschung gelöst werden kann.

Die letzten zwei Jahrzehnte der etymologischen Forschung in Ungarn sind thematisch und methodisch ungefähr durch folgende Momente charakterisiert: betont bleibt nach wie vor die Beschäftigung mit den Lehnwörtern; das hervorragendste Unternehmen auf diesem Gebiet ist die Monographie über die slawischen Lehnwörter des Ungarischen von István Kniezsa. Dieser Forschungsbereich wird auch dadurch erweitert, dass den allgemeinen und speziell ungarischen Problemen der internationalen Wanderwörter, Kulturwörter, der modernen Wörter von den Sprachwissenschaftlern immer mehr Aufmerksumkeit geschenkt wird. Neben der Erforschung der Lehnwörter wächst auch die Untersuchung der Wörter eigenen Ursprungs heran, besonders auf dem Gebiet der etymologischen Zusammenhänge zwischen Wörtern und Wortfamilien, der Wortspaltung, der Onomatopoetik, der verblassten Ableitungen und Zusammensetzungen. Das Voranschreiten der Methode wird gekennzeichnet durch das weitere Vordringen der Wortgeschichte, die ständig steigende Beachtung des ungarischen sprachgeschichtlichen Lebens der Wörter, die zunelımende Einbeziehung des Dialektmaterials, die Bestandaufnahme der Wortstämme im Zusammenhang mit den Endungen, die gruppenweise Bestandaufnahme der zur gleichen etymologischen Gruppe oder Familie gehörenden Wörter, die Zunahme der Rolle der Semantik und innerhalb derer der allgemeinen, vergleichenden Bedeutungslehre; ferner werden - last but not least - die kulturgeschichtlichen Beziehungen immer mehr in den Vordergrund gestellt. 
Den überaus weitverzweigten und grossangelegten Detailforschungen fehlte aber anch in dieser Zeit eine die Forschungen zusammenfassende und auf den gesamten ungarischen Wortschatz bezogene, angemessene Synthese. Zwar ist die Arbeit von Gríza Bárczi "A magyar szúkincs eredete» (Ursprung des ungarischen Wortschatzes) erschienen, die als Lehrbuch an den Universitäten gebraucht werden sollte, aber auch als wissenschaftliches Hilfsbuch brauchbar ist; diese in ihrer Art ausgezeichnete Arbeit konnte aber weder gattungsmässig noch in ihren Details eine zeitgemässe Synthese in Form eines etymologischen Wörterbuches ersetzen.

3. Diese Vorereignisse führen zum neuen ungarischen etymologischen Wörterbuch. Auf die Zusammenfassung und kritische Sichtung des in der ungarischen etymologischen Literatur gesammelten Materials auf zeitgemässer Ebene, bzw. auf die Ausarbeitung der Herkunft und der Geschichte des ungarischen Wortschatzes in einem umfangreichen Wörterbuch konnte nicht länger gewartet werden. Dieses Wörterbuch kann für das Weiterführen der wortkundlichen Untersuchungen neue Anregung geben, die Ergebnisse eines äusserst entwickelten Zweiges der ungarischen Sprachwissenschaft können dem Ausland vorgelegt und die zweifellos vorhandenen Ansprüche des gebildeten ungarischen Publikums können befriedigt werden.

Die Inangriffnahme der Arbeiten des Wörterbuches wurde im Jahre 1960 beschlossen und es wurde sofort mit der Verwirklichung begonnen. Noch im selben Jahr wurde der Plan des Wörterbuches ausgearbeitet und durchgesprochen; an ihm wurde auch jetzt, im Stadium der Verwirklichung nicht viel geändert. Über verschiedene Einzelheiten dieses Planes werde ich weiter unten, nach der Besprechung des Gepräges des Wörterbuches noch einiges sagen. Jetzt möchte ich nur die Grundelemente des Plines hervorheben.

Das Wörterbuch soll die wortgeschichtliche und etymologische Problematik der wesentlicheren Elemente des ungarischen Wortschatzes enthalten, und zwar ungefähr in 12000 Wortartikeln. Die Länge der Wortartikel hängt natürlich von der Art der in ihnen behandelten Wörter bwz. Wortfamilien $a b$; im Durchschnitt werden aber auf einen Wortartikel bei 
zweispaltigem Satz etwa $35-40$ Druckzeilen entfallen. Die Publikation des Materials soll in drei Bänden ron jo 1200 Seiten erfolgen. Das ganze Werk wird also ungefähr den zehnfachen Umfang des etymologischen Wörterbuches von Bárczi erhalten. Die inhaltliche, methodische und zeitliche Einheit des Werkes muss unbedingt gesichert werden, so dürfen die Arbeiten nicht verschleppt werden. In etwa einem Jahrzehnt müssen Ausarbeitung und Veröffentlichung durchgeführt sein und der erste Band muss im Jahre 1967, der letzte im Jahre 1973 erscheinen. - Die Herstellung eines Werkes von diesem Gepräge geht natürlich bei weitem über die Arbeitskraft von einigen wenigen Menschen, es kann also nur durch Zusammenarbeit, durch eine kollektive Beteiligung ungarischer Sprachwissenschaftler verwirklicht werden. Dementsprechend wurde die Arbeit als gemeinsames Unternehmen des Sprachwissenschaftlichen Instituts der Ungarischen Akademie der Wissenschaften und des Lehrstuhls der Eötvös Loránd Universität für Ungarische Sprachwissenschaft in die Wege geleitet. Mit der Organisation und der Leitung der Arbeit hat die Akademie mich beauftragt. Zur Zeit sind an der Ausarbeitung des Wörterbuches acht wissenschaftliche Mitarbeiter und vier Hilfskräfte mit ihrer vollen Arbeitszeit bzw. mit einem grösseren Teil derselben beteiligt; als freie Mitarbeiter, Sachverständige, Lektoren sind aber noch viele behilflich: sozusagen alle ungarischen Linguisten, die sich mit wortgeschichtlichen und etymologischen Forschungen beschäftigen. In der Mitarbeitergarde ist jedes Gebiet durch einen Spezialisten vertreten. Das finnisch-ugrische Material wird selbstverständlich in enger Zusammenarbeit mit den parallellaufenden Arbeiten des Werlies "A magyar szókincs finnugor elemei» (Die finnisch-ugrischen Elemente des ungarischen Wortschatzes) behandelt.

Die vorsichtige Sichtung des Wortmaterials und die Zusammenstellung des Stichwortverzeichnisses, die vorherige Ausarbeitung der grundsätzlichen und praktischen Problematik der Wortartikel, die Festlegung der Redaktionsvorschriften, das Schreiben der Muster-Wortartikel und im allgemeinen die nötige gegenseitige Abstimmung der Tätigkeit so vieler Personen nach allen Richtungen haben eine verhältnismässig lange, 
über ein Jahr dauernde Vorbereitung beansprucht. Nach deren Abschluss dauerte das Sammeln des Rohmaterials fast drei Jahre, es wurde am Ende des Jahres 1963 abgeschlossen. Während dieser Zeit wurde ein Katalog von etwa einer viertel Million Zetteln zusammengestellt und nach dem Stichwortverzeichnis geordnet; dieser umfasst die Bibliographie der Fachliteratur, die seit dem Jahre 1862 bis auf unsere Tage über die Etymologie ungarischer Wörter in ungarischen und ausländischen Zeitschriften, Handbüchern, Wörterbüchern nsw. zu finden sind. In derselben Zeit wurde eine wortgeschichtliche Sammlung durchgeführt, die die Neubearbeitung aller ungarischen Sprachdenkmäler bis zum Anfang des 16. Jahrhunderts bezweckt hat; aus diesem Naterial ergab sich nach den nötigen Rationalisierungen eine Sammlung von ungefähr hundertfünfzigtausend Zetteln, ebenfalls nach dem Stichwortverzeichnis geordnet. Diese letztere Sammlung ist freilich nur eine Ergänzung der wortgeschichtlichen Dokumentation des Wörterbuches, wir können uns ja auf eine ganze Reihe von Wörterbücherll und wortgeschichtlichen Wörtersammlungen stützen, ganz zu schweigen von dem Zettelmaterial unseres akademischen grossen Wörterbuches, das auf einigen Millionen Zetteln das ungarische wortgeschichtliche Material der letzten zwei Jahrhunderte erfasst hat.

Mit dem Schreiben des ersten Bandes des Wörterbuches wurde zu Anfang des Jahres 1964 begonnen. Bis jetzt sind die Wörter mit dem Anfangsbuchstaben $a, b, c, c s$ und $d$, zahlenmässig etwa zweitausend Wortartikel, abgeschlossen.

4. Nach Vorausschickung dieser grösstenteils äusserlichen Dinge wollen wir einen Blick werfen auf die inneren, inhaltlichen und methodischen Probleme des Wörterbuches, zeigen doch erst sie richtig, wie das Werk aussehen wird.

A) Die erste Frage, die wir hier beantworten müssen, sind der Charakter des zu bearbeitenden Wortmaterials und die Gesichtspunkte der Auswahl.

In unser Wörterbuch wurden nur Gemeinwörter aufgenommen, Orts- und Personennamen wurden - auf Grund prinzipieller und praktischer Erwägungen - ausgeschlossen. Die wichtigeren Elemente der letzteren gedenken wir später, nach 
Vollendung unseres Wörterbuches in einem besonderen ungarischen Eigennamen-Wörterbuch aufzuarbeiten. Die Eigennamen werden aber nur im Stichwortmaterial fehlen, sie werden bei der wortgeschichtlichen Dokumentation der Gemeinwörter natürlich sehr häufig vorkommen; ein bedeutender 'Tejl der alten ungarischen Gemeinwörter ist ja in Orts- und Personennamen $z u$ finden.

Es versteht sich von selbst, dass auch das Gemeinwortgut nur nach gehöriger Sichtung ins Wörterbuch aufgenommen werden kann, da der ganze Wortbestand der ungarischen Sprache die Zahl der aufnehmbaren Wörter vielfach übersteigt. Bei der Auswahl der Wörter haben wir uns nach dem Stichwortmateria] des "A Magyar Nyely Értelmező Szótíra" (Bedeutungswörterbuch der ungarischen Sprache) gerichtet, freilich mit gewissen Abänderungen. In erster Linje enthält das Wörterbuch die gemein- und schriftsprachlichen Wörter des Ungarischen. Auch die Kulturwörter des modernen Lebens meist internationaler Herkunft sind in dieser Gruppe vertreten, dic in der heutigen Gemeinsprache eine umfangreiche und sehr gebräuchliche Schicht bilden, die mit ihrer speziellen Problematik dem Wörterbuch Farbe und eigenen Reiz geben werden. Von den altsprachlichen, veralteten sowie mundartlichen Wörtern sind alle aufgenommen, die im Leben der ungarischen Sprache eine bedeutendere Rolle gespielt haben, folglich sprachgeschichtlich und dialektologisch reichlicher belegt werden können.

Die bereits früher erwälınten etwa 12000 Wortartikel des Wörterbuches bedenten nur in Stichwörtern und etymologischen Erörterungen eine ebenso grosse Zahl; die Anzahl der in den Wortartikeln behandelten, dokumentierten Wortindividuen übersteigt um ein Vielfaches die Grenze von 12000 . Alle Wörter nämlich, die auch der Laie als zusammenhängend, zu einer etymologischen Gruppe gehörig empfindet, werden in einem Wortartikel behandelt; so ist oft die ganze, aus einer Reihe von Wörtern bestehende Wortfamilie in einem Artikel zu finden. Diese Zusammenfassung wird aber nicht übertrieben, denn sie würde anch den Linguisten im Gebrauch Schwierigkeiten bereiten, mnd die Iaien könnten sich nur äusserst schwer zurechtfinden. Dementsprechend werden wir jedes Wortindi- 
viduum und jede Gruppe, die sich von ihrer Familie mehr oder minder getrennt haben, in einem besonderen Artikel bearbeiten: z. B. die verblassten Ableitungen, die stärkeren Bedeutungsdifferenzierungen, die sonderbaren, mnregelmässigen Bildungen der Sprachernenerung, auch die verblassten, sowie kulturgeschichtlich wichtigen, interessanten Zusammensetzungen usw.

B) Im Aufbau der Wortartikel ist der erste Teil der sog. wortgeschichtliche Teil, der das geschichtliche Leben des Wortes und seiner Familie in der ungarischen Sprache darstellt. Hierauf wird grosses Gewicht gelegt, da wir auf dem prinzipiellen Standpunkt der Zusammengehörigkeit, der Untrennbarkeit von Wortgeschichte und Etymologie stehen, was - wie bekannt - in Ungarn wissenschaftsgeschichtliche Überlieferung ist. Nach unserer Auffassung stehen die Herkunft und das sprachgeschichtliche Leben eines Wortes im engsten Zusammenhang miteinander: die Zeit des ersten Vorkommens, die früheren Gebrauchsweisen, die sprachgeschichtlichen Form- und Bedeutungsvarianten des Wortes geben uns sehr häufig die Handhabe zur Lösung der etymologischen Fragen und beeinflussen fast in allen Fällen die Stelhnngnahme in der Gänze oder zumindest in einigen Einzelheiten der Etymologie. Durch die ausfïhrliche wortgeschichtliche Dokumentation wollen wir natürlich kein spezielles sprachgeschichtlich-wortgeschichtliches Wörterbuch ersetzen (ein solches ist gegenwärtig ebenfalls in Vorbereitung), wir wollen vielmehr ausgewählte Daten bringen, die das Leben des Wortes in frappanter Weise beleuchten.

Die Einteilung des wortgeschichtlichen Teiles der Wortartikel ist folgende: Nach dem Stichwort folgt der erste Beleg - bei alten Wörtern meist als Eigenname - mit dem Kontext. Das erste Vorkommen als Gemeinwort wird ebenfalls im Kontext gegeben. Dieser Teil enthält die altsprachlichen und mundartlichen Formvarianten des Wortes der Zeitfolge nach (Schriftvarianten natürlich nicht), auch seine Bedeutungsvarianten. Dieser Aufzählung folgen, ebenfalls in der Zeitfolge, die Belege der wichtigeren Ableitungen. Alle diese Belege geben das jeweilige erste Vorkommen der Varianten, buchstabengetreu und mit genauer bibliographischer Angabe des Fundortes. Die Bedeutungen, die in die Gemeinsprache aufgestiegen sind, werden durch besondere Zeichen hervorgehoben. 
Wie viele Formvarianten, Bedeutungsvarianten und Ableitungen in die einzelnen Wortartikel aufgenommen werden, hängt natürlich $a b$ rom Charakter des behandelten Wortes bzw. der Wortfamilie, und ist demnach sehr verschieden. Auf Grund der bisher ausgearbeiteten Wortartikel kann man sagen, dass das ganze Wörterbuch ungefähr 140000 solche Daten mit Jahreszahl und Quellenangabe enthalten wird, ungefähr in folgender Verteilung: 60000 Formvarianten, 30000 Bedentungsvarianten, 50000 Ableitungen.

C) Den zweiten Hauptteil der Wortartikel bilden die etymologischen Erklärungen. Bei unseren Stellungnahmen stützen wir uns auf die Ergebnisse der bisherigen Fachliteratur, die jedoch lediglich als rrundmaterial botrachtet werden. Dies bedeutet, dass wir nicht sämtliche, oft auseinandergehende Meinungen anführen, die für das fragliche Wort oder die Wortfamilie bisher vorgebracht wurden, sondern wir geben in jedem Fall die von der Redaktion des Wörterbuches einheitlich gebildete und formulierte Stellungnahme. Bei Wörtern mit umstrittener Herkunft ist diese natürlich alternativ oder sogar mehrartig; dann geben wir die nennenswerten Erklärungen in der Reihenfolge ihrer Wahrscheinlichkeit, numeriert. Auf die irrigen Erklärungen weisen wir nur hin, ohne sie ausführlicher zu widerlegen. Wegen der Ungleichmässigkeit und Fehler der bisherigen Erklärungen müssen natürlich zahlreiche Etymologien neu ausgearbeitet oder zumindest ergänzt, umgewertet werden. Dies geschieht aber nie nach individueller Willkür: wie jeder einzelne Teil der Wortartikel geht auch der etymologische Teil wenigstens durch die Hände von sechs Bearbeitern; seinem Inhalt müssen also der Schreiber des Artikels, zwei Redakteure, der Chefredakteur, der aussere Sachverständige und der Lektor beistimmen.

Wir sind bestrebt, den etymologischen Teil in gemeinverständlicher Form, auch für das breite Publikum zugänglich zu gestalten. Deshalb deuten wir im einleitenden Satz dieses Teiles gleich an, was unsere Meinung bezüglich der Herkunft des Wortes ist. Erst nach dieser Einleitung folgt die ausführliche Darlegung, in der das Streben nach Gemeinverständlichkeit die fachlichen Gesichtspunktr nicht in den Hintergrund drängen darf. Bei Wörteru fimuisch-uyrischer Herkunft, bei 
Lehnwörtern und internationalen Wörtern geben wir möglichst viel fremdsprachliches Vergleichsmaterial mit den nötigen Quellenangaben. Auch bei der Erklärung der ungarischen innersprachlich entstandenen Wörter haben wir die genaue Dokumentation im Auge, indem wir die hier befolgten etymologischen Prinzipien und Methoden nach den bei uns in neuerer Zeit üblichen richten. Ausser den nötigen phonetischen, morphologischen und semantischen Erklärungen wird grosses Gewicht. gelegt auf die Darstellung des sachlichen, volkskundlichen und kulturhistorischen Hintergrundes eines Wortes. Von Bedeutung sind ferner die fremdsprachlichen Analogien. Wir kümmern uns nicht nur um die Herkunft der Wörter, sondern erklären auch - in engem Zusammenhang mit den wortgeschichtlichen Angaben - die wichtigsten Momente ihres Lebens (formale und semantische Wandlungen, ( Gestaltung des Anwendungsbereiches usw.), falls sie einer Erklärung bedürfen.

Wir beschäftigen uns aber nicht mit der Problematik der Aufnahme ungarischer Wörter in fremde Sprachen, bzw. berühren wir diesen Problembereich nur bei solchen Lehnwörtern, wo die Herkunft des Wortes ungeklärt ist und die Möglich-

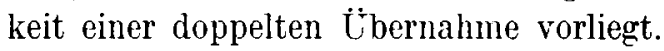

D) Den dritten Teil im Aufbau der Wortartikel bilden dip bibliographischen Angaben der etymologischen Literatur. Die Bestandaufnahme der etymologischen Vorarbeiten ist ebenfalls eine Tradition der ungarischen Sprachwissenschaft. Doch halten wir an ihr nicht nur deshalb fest, sondern auch darum, weil dies einerseits mit der wissenschaftlichen Ethik, andererseits und vor allem mit den wissenschaftlichen Erfordernissen in Einklang steht, den Interessen der Forschung dient. In der umfangreichen ungarischen wortgeschichtlich-etymologischen Literatur finden sich Bemerkungen, Erörterungen über die meisten Wörter in ansehnlicher Menge; manche Etymologien wurden von einer ganzen Reihe von Linguisten herausgebildet, indem jeder von ihnen etwas hinzutat oder wegnahm. In unserem Wörterbuch sind die etymologischen Stellungnahmen zum grössten Teil auf dieser Literatur aufgebaut, sie wird kritisch zusammengefasst; innerhalb eines Wortartikels reichen jedoch die wenigen Zrilen der Etỵmolngie bei weitem nicht aus, den 
ganzen Fragenkomplex der einzelnen Wörter zu erfassen und die damit verbundenen -- manchmal gar nicht unwesentlichen - Einzelheiten aufzudecken. Für den Forscher ist jedoch --. wie wir wissen - ein ausführliches Literaturverzeichnis von unendlich grossem Nutzen: er kann damit nicht nur die gegebene Erklärung kontrollieren, sondern auch bedeutend ergänzen, er kann den gesamten Verlauf ihrer Entwicklung und die ganze Problematik derselben kennenlernen.

Es gibt Wörter und Wortfamilien, deren Problematik in der Bibliographie der Fachliteratur etwa 80 bis 100 Angaben enthält. Gerade aus diesem Grunde mussten in dieser Hinsicht Einschränkungen vorgenommen werden. Wir haben auf das Material aus der Zeit vor dem Jahr 1862 verzichtet, auf weniger wichtige, peripherische Bemerkungen, auf einfache Wiederholungen früherer Ansichten, auch auf bibliographische Daten von unwissenschaftlichen Erklärungen. Auch so werden die bibliographischen Daten unseres Wörterbuches die Zahl 160000 überschreiten. Der besseren Orientierung wegen werden wir bei allen bibliographischen Angaben jene wenigen Daten durch ein besonderes Zeichen hervorheben, die für die Etymologie und die Geschichte des Wortes besonders wichtige oder besonders ausführliche Bemerkungen versprechen. Alle bibliographischen Angaben enthalten übrigens den Familiennamen des Verfassers, die Abkürzung des Werkes, die Band- und Seitenzahl.

E) Hinweise auf Wörter, die mit dem behandelten Wort in irgendeinem Zusammenhang stehen, schliessen den Wortartikel. Da unser Wörterbuch einesteils auf die Klarlegung der ursprünglichen Zusammenhänge und die entwicklungsgeschichtlichen Wechselwirkungen zwischen den Wörtern und Wortfamilien grosses Gewicht legt, andererseits - wie erwähnt - die etymologisch letztlich zusammengehörigen Wörter und Wortfamilien, die aber von den Laien nicht mehr als verwandt empfunden werden, in besonderen Wortartikeln behandelt werden, so werden diese Hinweise überaus zahlreich sein und im Wörterbuch einen sehr wichtigen Teil bilden.

5. Das Wörterbuch wird in ungarischer Sprache erscheinen, doch werden die Bedeutungen und gewisse Termini technici 
im Text auch deutsch angegeben. Wahrscheinlich werden wir aber in den siebziger Jahren einen kürzeren Abriss des Wörterbuches auch in einer fremden Sprache herausgoben.

J JORÁND BENKö

\section{Probeartikel}

ad 1130-40: "VII aratra bovum cum XIII mansionibus, nomina quorum hec sunt: Belta, . . Odun, ..." szn. sz. [PRT. 8: 270]; $1195 \mathrm{k}$.: "el odutta vola neki paradifumut hazóá [HB.]; 1211: ? Adomas szn. sz. [OklSz.]; $1420 \mathrm{k} .:$ ette [OMOlv. 283]; $1490 \mathrm{k} .:$ aad [AporK. 15]; $1512 \mathrm{k} .:$ el addatik [Weszpr K. 22]. $J$ : ált. 'g e b e n'; 1.1195 k.: 'juttat; hingeben! ajándékoz; schenken' [l. fent]; 2. $1448 \mathrm{k}$ : 'szolgáltat; liefern' [JókK. 119]; 3. 1450 k.: 'megenged; erlauben' [BécsiK. 2]; 4. 1466: 'elad; verkaufen' [MünchK. 140]. - - Sz: ás 1272/XV. sz.: ? adasa [MNy. 10: 135], $1395 \mathrm{k}$ : adasz [BesztSzj. 66.] $§ \sim a t 1405 \mathrm{k} .:$ adath 'adas' [SchlSzj. 249.], 1815: 'adag' [NyÚSz.], 1831: 'kiegészítés' [Kreszn.] $§ \sim a k o-$ $z i k 1448 \mathrm{k}$ : adakzny [JókK. $81 \mathrm{v}$.] $\$ \sim o m a ́ n$ y $1450 \mathrm{k}$.: adomañit [BécsiK. 142] § o gat 1533: adogatta [Komj: SzPál. 228: NySz.] § $\sim t a$ [szitokszó] 1636: Eb atta [OklSz.] $\sim a l e ́ k$ 1645: adalékokat 'hagyomány' [GKat: Váltság Titka 2: 203: RNySz. 434], 1841: 'kiegészítés' [NyÚSz.] $₹ \sim$ ód i k 1702: adódik [DEmb: GE. 9: NySz.] $\sim t a ́ z$ 1776: attázni 'szitkozódik' [Rakovszky S.: Rendes élet 6: NSz.] \& o má ny oz 1807: adományzott [NyỨSz.] § a g 1831: adag [NytíSz.] § $\sim a$ t ol 1864: adatolni [NyÚSz.] $₹ \sim a g$ ol 1872: Adagolni [Ballagi].

Finnugor eredetü; vö.: zürj. V. udni 'etet, itat'; votj. Sz. ud- 'ua.'; mord. E. andoms 'táplál'; finn antaa [>lp. N. âd'det] 'ad'; lp. N. vuow'det 'elad' [Niels.]. A kikövetkeztethetö alapnyelvi *amta alakból valamennyi finnugor nyelvi szó hangtörvényszerüen következik. - Az $a d \sim a ́ d$ párban az utóbbi másodlagos. Valamennyi magyar és rokon nyelvi jelentés a 'geben' jelentésböl vezethetö le.

MUSz. 716 +; Szinnyei: NyH. ${ }^{1-7}$; Wichmann: MSFOu. 21. sz. 25; EtSz.; Horger: MNy. 10: 114; SzófSz.; Steinitz: FgrVok. 35; SKES. +; Collinder: FUV. +, UrGr. 145, 388, ${ }_{4} 10$; E. Itkonen: UAJb. 28: $68+$; Erdélyi: NyK. 65: 390 +; MSzFgrE. +. - Vö. ad $\delta$, ado ma.

áfonya 1708: "Havasi tsere [znye, Afonya termés" [PP. Myrtillus a.]; 1708: Afonnya [PP.]; 1763: Affonya [Adámi: Wb. 1: NSz.]; $1795 \mathrm{k}$. : áfonya (Takáts: Told. M.r.: NSz.]; 1801: Afonnya [PP.]; - áfanya, áfinya [ÚMTsz.]. $J$ : 1. 1708: 'áfonyabogyó; Heidelbeere' [l. fent]; 2. 1708: 'áfonyacserje; Heidelbeerstrauch' [PP.]; szakny. 'Vaccinium'.

Valószinüleg román eredetú; vö. rom. áfină, afină, E. afună 'áfonya [bogyó]', áfin 'fekete áfonya[cserje]'. A román szó az aruménban is 
megvan, ezért a magyarból való származtatása valószínütlen. A román szó egyébként nyilvánvalóan összefügg a szlk. hajera, hafira, hafura; jafira, jafura; le. afyna, jafer; ukr. ıfuna, sifuna, úgupa: 'áfonya' szavakkal; e szócsoport etimológiảja nincs tisztázva. - - Az áfonya az erdélyi nyelvjárásokból került a magyar köznyelvbe.

Budenz: NyK. 6: 300; Szarvas: Nyr. 2: 536 +; Szinnyei: Nyr. 22: 25, 81 +; Damian: NyF. 67. sz. 45, 46; EtSz. +; Drăganu: Dac. 1: 133; 'Treml: IngJb. 9: 296, NyK. 48: 98; Crânjală: RumVl. 198; SzófSz.; Blédy: Infl. 18; Bakos: Nyr. 76: 444, Machek: CSlImR. 179; EtSICSI. 120; Cioranescu: DiccEtRum. 10; Szabó T.A.: NyJrk. 4: 302.

akar 1290 - 5: ? "tota terra ipsarum villarum, scilicet Akaratia circumiacet in metis" hn. sz. [Turul 29: 130]; 1420 k.: "ackarode...: wildu ... haben" [ÓMOlv. 283]; 1519: akarattaak [JordK. 561]; 1536: akorom [MNy. 10: 377]. $J$ : ált. 'wollen'; 1. $1420 \mathrm{k}$ : 'óhajt; w ü ns c h e n' [l. fent]; 2. 1448 k.: 'törekszik < valamire $>$; t r a c h t e $n$ $<$ nach etwas >' [JókK. 6]; 3. 1450 k.: 'szándékozik; v or h a be n' [BécsiK. 5], - - S z: $\sim a t 1290-5$ [1. fent], $1448 \mathrm{k}:$ akaratyaual [JókK. 4] $₹ \sim$ a to $s 1448 \mathrm{k}$.: akaratos 'önkéntes' [JókK. 58]; 1552: 'erőszakos' [Heltai: Dial. F3a] $\S \sim a t l$ a $n$ 1636: akaratlanságokbol sz. [NyÚSz.] $\S \sim a t o s k o d i k$ 1675: akaratoskodik [Szönyi: Mártir. Kor. 181: NySz.] $₹ \sim o[d] z i k$ 1831: akarózott [Irod. Közl. 4: 481: NSz.] $\sim$ nok 1892: akarnok [MNy. 5: 78].

Talán ugor eredetũ alapszó származéka; vö.: vog. K. änkwèti [VNGy. 4: 376], P. āñkwèti, AL. añgurmäti, F. ānkwērmäti, ānköwäti [sg. 3. sz.]:

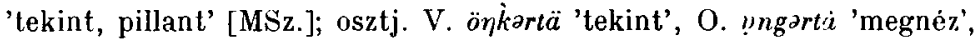
Kr. ǎykarmatí 'feltekint'. Ohi-ugor szóbelseji $\eta k \sim$ magyar $k$ megfelelés biztos etimológiában nincs. Az egybevetés bizonytalanságát fokozza, hogy az osztják nyelvjárási alakok magashangú elözményre vallanak. Ha az ugor szavak mégis közös eredetüek, az $-r$ igeképzö esetleg már az ugor alapnyelvben hozzájárulhatott az alapszóhoz. A 'lát, tekint' $\rightarrow$ 'akar' jelentésváltozásra vö.: ném. absehen auf etw' 'valamire tekint, ránéz' $\rightarrow$ Absicht 'szándék'; lat. spectare '[meg]néz' $\rightarrow$ 'törekszik valamire'.

MUSz. 727 +; Gombocz: NyK. 39: 239; Wichmann: FUF. 11: 183; Etsz. +; SzófSz.; Steinitz: OstjGramm. 136; Grétsy: Szóhas. 211; MSzFgrE. +. - - Vö. $a k \dot{a} r$.

alakor 1440: "Viginti quinque cumulos bladorum vulgo Alakar habitorum* [OklSz.]; 1493: alakor [OklSz.]; 1906: alakór [NyF. 29. sz. 29]. J: 1. 1440: 'tönköly; Dinkel' [l. fent]; 2. 1673: 'keveréktakarmány; Mischfutter für das Vieh' [Com: Jan. 27: NySz.]; szakny. 'Triticum monococcum'.

Vitatott eredetū. - - 1. Román jüvevényszó; vö. rom. alac 'tönköly'. E román szó etimológiája nincs tisztázva. - A magyarba vagy 
az artikulusos rom. alacul kerülhetett át - ez esethen a. m. alakor r-je elhasonulással keletkezett - -, vagy pedig egy ki nem mutatott, de feltehető többes számú rom. *alacuri. . - i in. R., X. alak 'keveréktakarı́ńny; másodrendü árpa' [1647: Etšz. 2. alak a.] az alapalakú rom. alac átvétele. - - 2. Jövevényszó egy olyan ismeretlen nép nyelvébỏl, amelyik a honfoglaláskor a Kárpátok medencéjében élt. A tönköly ezen a tájon prehisztorikus idők óta ismeretes. A $\mathrm{m}$. alakor és a rom. alac ugyanabból a forrásból származhat, bár a román szónál a magyar közvetítés is számításba jöhet. - - Nyelvjárási és szaknyelvi szó.

Edelspacher: NyK. 12: $95+$; Szinnyei: Nyr. 22: 27+, 387; Alexics: Nyr. 34: 198:, Simonyi: MNyelv. ${ }^{2}$ 84; Horger: Nytud. 2: $42+$, EtSz. 1. alakor a.; Treml: MNy. 25: 47, UngJb. 8: 43, NyK. 48: 97; Tamás: Róm. 199; Drăganu: Dac. 7: 201; Győrffy: MsgNépr. 2: 188; Blédy: Infl. 19; Gáldi: DictKlein 170; Gunda: Ethn. 58: 308, EtSl-Roum. 1: 231, 253; Bárczi: Szók. ${ }^{2}$ 120; Szabó T. A.: NyIrK. 4: 302; StUBB. 1960. 2: 18, 23, 24, 1962. 2: 14, 15, 20: Molnár N.: Növ. 9.

álmelkodik 1495 e.: sel almelcodanac az $\mathrm{v}$ nag zeplegen" [Guary K. 109], de l. álmél; $1508 \mathrm{k}$ : amulcoda fara sz. [Sim K. 13]; $1519 \mathrm{k} .:$ el amolkoduan [DebrK. 32]; 1529 e.: el almelkodek [Virg K. 33]; 1532: amilkodo [TihK. 287]; $1600 \mathrm{k}$ : el almilkodot [BrassSzt. 10.]. De vö. 1580: el almol [Tel: Evang. 1: 88: NySz.]. $J: 1.1495$ e.: 'csodálkozik; s t a u n e n' [l. fent]; 2. 1508: 'megrémül; erschrecken' [NádK. 68]; 3. 1513: 'elbágyad; betäubt werden' [NagyszK. 210] \$§ álmél 1'́56 k.: "et obstupuerunt megrezjedenek vel ijedenek auag elamelanakh" [SermDom. 2: 161]. $J$ : 1. 1456 k.: 'megrémül; erschrecken' [l. fent]; 2. 1519: 'csodálkozik; staunen' [JordK. 714]; 3. 1580: 'elbágyad; betäubt werden' [Tel: Evang. 1: 88: NySz.]. - - $S z: 1456 \mathrm{k} .: \sim$ ás elamelas [SermDom. 2: 515].

Magyar hangfestö eredetü szócsalád: a szájtátást, bámészkodást kifejezö ám - hangkapcsolatnak -l, -lkodik képzővel a visszaható igék rendszerébe való beilleszkedése ítján keletkezett. Az álm- tö $l$-je szervetlen járulékhang [vö.: boldog, bölcsö, hold]. A jelentések a 'szájat tát' alapjelentésböl ágazhattak el: 'ijedtségében, csodálkozásában szájat tát' $\rightarrow$ 'megijed' $\rightarrow$ 'csodálkozik' $\rightarrow$ 'elbágyad, eltompul'. Az alszik ige al- tövéböl való származtatása, az álom, álmodik, valamint az im, igy mutatószókkal való rokonitása téves.

CzF.; MLSz. 744; Simonyi: Nyr. 10: 321, NyK. 16: 252; Szeremley: MNy. 4: 341; Gombocz: NyK. 39: 236, 258; EtSz.; Kallós: Nyr. 63: 120; Benkö: MNy. 50: $269+$; MSzFgrE. +. - Vö.: ámolyog, á $m u l$.

$a^{2} 1300$ k.: "Scemem kunu el arad» sz. [ÓMS.]; 1405 k.: "ar viz: torrens" [SchlSzj. 775.]; 1450 k.: arrada sz. [BécsiK. 72]; 1566: "a nagy ar hozot ide» [Heltai 64. Fab.: MFl.]; 1833: arjad sz. 'árad' [Kassai 1: 187]. $J$ : 1. 1300 k.: 'vízár; F l u t' [1. fent]: 2, 1508; 'nagy mennyiség; grosse 
Quantität' [DöbrK. 34]. - $S z: \sim a d 1300 \mathrm{k} .:$ 1. fent $\S \sim a d a t$ $1350 \mathrm{k}$ : a ra d a t i a 'származás' [KTSz.], 1450 k.: 'víz áradása' [BécsiK. 310] § ad ás 1517: arradalabol [DomK. 120] $\sim a s z t$ 1527: araztany [ÉrdyK. 64] $\sim a d o z[i k]$ 1770/1914: áradozni [Bokréta 92: NSz.].

Ugor eredetü; vö. vog. AK., Szo. tūr, AL. tor: 'tó'; osztj. V. lar, VJ. iar: 'árterület', O. lar 'árterület, tó', Kr. tor 'tó'. Zürjén és votják egyeztetése téves, igy az ugor-permi kapcsolatok feltevésének ezen az alapon való támogatása elesik. Egyéb finnugorságbeli és szamojéd szavak idekapcsolása helytelen. A szó az ugorság vízben gazdag lakóhelyén fontos szerepet játszó jelenségre utalt. A magyar szócsalád késóbbi életében felmerülö jelentésmozzanatok: 'nagy mennyiség, bőség', 'gyors sodródás', 'valahonnan való eredet, származás', amelyek föleg a származékokban és a szócsalád tagjainak átvitt értelmü alkalmazásában uralkodóvá váltak, kivétel nélkül megtalálhatók mint részletelemek az alapszó eredeti jelentésében. Az elavulófélhen levô szócsaládot Baróti Szabó Dávid elevenitette fel [1784: $A$ r, 1792: Aradat]. A nyelvujititás korában a szó családja még más, nagy jövőjü tagokkal gyarapodott [l. áramlik]. - A szónak török, mongol, kaukázusi és árja származtatása, valamint másféle finnugor egyeztetése téves.

CzF.; Vámbéry: NyK. 8: 127; Budenz: NyK. 10: 61, 63, 94, 17: 476; MUSz. 750; Bálint: Párh. 2; Simonyi: AkNyÉrt. 9/12: 22, NyK. 16: 261, Nyr. 29: 483; Thúry J.: EPhK. 9: 270; Munkácsi: Ethn. 4: 292, ÁKE. 134, 644; Setälä: FUF. 2: 256 +; NyÚSz.; EtSz. 2. ár a.; Schmidt: Nyr. 53: 55; Tolnai: Nyúj. 205; Mészöly: SzegFüz. 3: 125; SzófSz.; Bárczi: MNy. 39: 287, TihAl. 176, Nyr. 80: 4; Hajdú: NytudÉrt. 2. sz. 45; B. Lörinczy: KTSz. 163; D. Bartha: Szóképz. 58; MSzFgrE. +. - Vö. áramlik.

árboc 1470: „Hujus naviculae prora haionak orra ... arbox arbor crux Christi, velum spes" [SermDom. 2: 698]; 1519: ? arbozon [JordK. 466]; 1533: Arbocz fa ö. [Murm. 1296.]; 1552: árboß fa ö. [Heltai: Dial. E1a]; 1560 k.: arboch fayanak ö. [GyöngySzt. 1549.]; 1763: Arbocz-fa ö. [Adámi: Wb. 5: NSz.]; 1772: árbótz-fát ö. [Mészáros Ign.: Kartigám 196: NSz.]; 1777: árbutzfa ö. [Baróti Szabó: Új mért. 2: NSz.]; 1792: arbutz [SzD. Árbotz a.]; 1824: Árbaczokon [Guzmics I.: Theokritosz 66: VSz.]; - - ábroc, ábrucfa ö., árgucfa ö. [ÚMTsz.]. J: 1. 1470: 'hajóárboc; M a s t' [1. fent]; 2. 1527: 'fenyö; Tanne' [ÉrdyK. 578]; 3. 1555: 'rúd; Stange zászlórud; $\mathrm{F}$ a h n e $\mathrm{n}$ s t a $\mathrm{n} \mathrm{g}$ e' [Tin. 247: NySz. 1: 733 ].

Valószínủleg latin eredetü; vö. h. lat. arbos 'fa' [GyöngySzt. 1843.], lat. arbor, R. arbos 'élő fa; árboc; evezô; hajó; hajítódárda, gerely'. - . A magyar alakváltozatok közül a cs végüek a szabályszerủ s-ezö magyarországi latin kiejtésnek megfelelő alak folytatói, a $c$ végủek az eléggé kérdéses sz-szel ejtett forma affrikálódással keletkezett megfelelői. A latin származtatásnak jelentéstani akadálya nincs, de az emli- 
tett hangtani rendellenesség mellett további nehézsége e magyarázatnak az is, hogy mint hajózási müszónak -- ha ugyan a magyarban valóban eredetibb az 1., mint a 2 . és 3 . jelentés - kevéssé valószinü a latin eredete. Egy ilyen mủszó forrása inkább lehetne valamely élö nyelv. Ha azonban feltesszük, hogy a szó tudós úton terjedt el, ezek a nehézsẻgek kevésbé jelentősekké válnak. A kérdés még tüzetes vizsgálatra szorul. - A régi nyelvben sokkal gyakoribb árbocfa összetételböl az. árboc talán Baróti Szabó Dávid tudatos elvonása.

Budenz: NyK. 6: 300; Simonyi: Nyr. 5: 29, 6: 447, NyF. 11. sz. 6, Nyr. 46: 27 +; Edelspacher: Nyr. 7: 433; Kovács: LatEl. 9; Rell: LatSz. 32; Gombocz-Melich: MNy. 2. 308; Melich: Nyr. 36: 164, MNy. 5: 388, Syh. 39: 34, MNy. 6: 295, 11: $138+, 19: 38$, AkNyÉrt. 25/4: 40; Simai: MNy. 5: 267, 6: 316; Szinnyei: NyK. 42: 3; EtSz. +; Spitzer: Nyr. 44: 21 +; Gombocz: ÖM. 2/1: 81, LngJb. 8: 271; Tolnai: Nyúj. 47; Fludorovits: MNy. 26: 50, 373, LatJsz. 28, 41, 43; SzófSz.; Deme: MNyTK. 69. sz. 31; Gáldi: Szótir. 20, 52, 92; Bárczi: Szók. 105 - ; Kniezsa: NyK. 60:481 +, 61: 276. [Wartburg: FEW. 1: 124.] 